\title{
War, trauma and culture: working with Tamil refugees and asylum seekers using culturally adapted CBT
}

\author{
Meera Bahu ${ }^{\S}$ \\ Wandsworth IAPT, St Georges Mental Health NHS Trust, London, UK \\ Corresponding author. Email: meera.bahu@nhs.net
}

(Received 29 April 2018; revised 12 May 2019; accepted 07 August 2019)

\begin{abstract}
This study explores the mental health difficulties associated with severe trauma as experienced by refugees and asylum seekers, and issues related to psychological treatments. An evaluation was conducted of a culturally adapted cognitive therapy group programme for Tamil refugees and asylum seekers in the Wandsworth IAPT (Improving Access to Psychological Therapies) service. Data were examined from 16 Tamil participants who accessed the service between 2014 and 2015 and subsequently engaged in the group programme between 2015 and 2016. The IAPT minimum data set (PHQ9, GAD-7, Phobia scale and WSAS) and IES-R (Impact of Events Scale Revised) were used as quantitative measures. Qualitative feedback about the programme was also obtained. A positive change in the wellbeing of participants was indicated by a reduction in the severity of negative symptoms for all metrics and qualitative feedback provided additional evidence that participants had benefited from the programme. The implications of these findings are discussed.
\end{abstract}

\section{Key learning aims}

(1) To examine the difficulties experienced by refugees and asylum seekers and to provide a shared understanding of these themes for CBT practitioners.

(2) To assist CBT practitioners to develop their confidence in using culturally adapted CBT treatment programmes for refugees and asylum seekers.

(3) To inform service providers how culturally adapted CBT models can be used in developing specialist services for refugees and asylum seekers.

Keywords: collective trauma; culturally adapted CBT; primary care; refugee trauma; Tamil clients; Tamil community

\section{Introduction}

\section{War, trauma and migration}

It has been identified that there have been around 150 so-called 'low intensity' wars in poor third world countries since 1945, with around $90 \%$ of casualties involving the civilian population (Summerfield, 1995). The United Nations High Commissioner for Refugees (UNHCR) annual global trend study indicates that 65.6 million people were forcibly displaced worldwide at the end of 2016 - a total larger than the population of the United Kingdom (UK) (UNCHR, 2016).

These wars often serve to exert social control by disrupting social, economic and cultural structures. The norms of these atrocities are bombing, shelling, mass displacements, disappearances, and physical, psychological and sexual torture.

\footnotetext{
${ }^{\S}$ The author is committee member and secretary for the BABCP's Equality and Culture Special Interest Group.
} 
Asylum seekers and refugees suffer from the psychological impact of this trauma. They are also likely to have experienced the social and economic stresses of forced migration, seeking refuge in another country as a result of being persecuted or submitted to political violence, war and torture. They may have suffered many losses including losing their home, property, job, culture, traditions, family, friends and health. The journey to another country is traumatic, difficult and filled with threats and dangers. Many refugees arrive as illegal immigrants and some live in hiding without proper medical care and housing.

Most of the refugees arriving in the UK submit a request for asylum and until this request is granted they have minimal rights. One hundred and forty-four countries including the UK have committed to not sending people back who are in danger of persecution (UNCHR, 1992). However, the UK Home Office has been criticized for poor-quality decision making over asylum claims. These include decisions that are based on inaccurate and out-of-date country information, unreasoned decisions about people's credibility and a failure to properly consider complex torture cases. Furthermore, it has been reported that the Home Office can ignore relevant evidence such as medical reports and base refusal on inaccurate and incomplete information (Amnesty International, 2004; Asylum Aid, 1999; Smith, 2004).

At times, asylum seekers are imprisoned as they may not have the proper travel documents and are taken into closed refugee camps. The process of seeking asylum incurs high levels of stress due to court hearings where there is a lack of understanding about the impact of trauma. Despite the often rather fragmented nature of traumatic memories, refugees are asked to reproduce their experiences in a chronological and rational manner. This increases pressure on the individual and the risk of them being sent back to the country from which they fled.

These bureaucratic processes can add to the stress already being experienced by refugees and asylum seekers and increase the likelihood that they will become highly suicidal. Additionally, by recounting their experiences in an uncontained manner, there is also a risk that they become re-traumatized. Laws and Patsalides (1997) found that the interview situation itself can trigger similarities to torture situations and earlier feelings of powerlessness. They caution that despite adequate precautions, psychological and medical interviews and examinations may re-traumatize asylum seekers. For example, according to Herlihy (2003), small interview rooms may remind refugees of places where they were previously tortured.

Regarding disclosure, it has been found that rape and sexual abuse victims experience shame and guilt when they re-tell their stories, and there is a tendency to avoid re-telling (Derlega et al., 1993). Brown et al. (1999) found negative affect post-disclosure and the studies of McNulty and Wardle (1994) show that disclosure of sexual abuse can lead to psychological distress.

Furthermore, there are cultural issues that can also play a role in the self-disclosure of distressing events; more research is needed in this largely unexplored area (Farber and Hall, 2002).

In relation to an updated report on recent developments in UK asylum practice and law, Maurice Wren, Chief Executive of the Refugee Council reported that: 'despite a growing body of evidence pointing to the harm caused by detention, the UK continues to make arbitrary deprivation of liberty a mainstay of its asylum and immigration policy' (Asylum Information Database, 2018).

\section{Issues relating to psychological treatment of refugees}

It is important to find and use effective and evidence-based therapies for refugees who have been subjected to multiple traumatic experiences. However, a number of issues emphasize the complexity of this task.

Research studies indicate that refugees show a greater level of psychological distress than the general population and this includes higher rates of major depressive disorder and post-traumatic stress disorder (PTSD) (Fazel et al., 2005; Porter and Haslam, 2005).

With specific reference to PTSD, Moisander and Edston (2003) found that the prevalence of this disorder ranged from 69 to $92 \%$ across all patient groups in their comparison of 160 refugees from six different nations who had been tortured in their homeland. 
With regard to self-harming and suicidal behaviours, in 2015 there were 393 recorded suicide attempts amongst the UK's detained asylum seeker population and 2957 detainees were on suicide watch including 11 children [as was reported in The Guardian (Taylor, 2016)]. In fact, since January 2007 there have been over 20,423 persons on suicide watch and 2978 attempted suicides across the UK detention centres ('No-Deportations - Residence Papers for All', 2018)

Difficulties and dilemmas may arise in psychological therapy as refugees and asylum seekers have often endured multiple traumatic events in their home land but then as noted above, can experience ongoing trauma in their host or new country. Furthermore, refugees and asylum seekers come from culturally and linguistically diverse backgrounds and may have needs that are not adequately met by the existing services in their new country. Changes in social roles (Colic-Peisker and Walker, 2003), unemployment and financial difficulties (Beiser and Hou, 2001) and social isolation (Miller et al., 2002; Mollica et al., 2001) add to the difficulties faced by asylum seekers and refugees. Media hostility and the perception that refugees are burdens on society can also cause great distress. Overall, all the above factors can influence an individual's willingness to engage with others (Gurtman, 1992).

All of these issues pose great challenges for therapists treating refugees and asylum seekers as therapists often find it difficult to meet their complex needs and maintain the trust and engagement of the refugee population. It should also be recognized that clinical staff need support, training, adequate supervision and extra treatment time to process these complexities. According to van der Veer (1998), it is important that therapists can share traumatic stories from clients and reflect on their therapeutic work in supervision to prevent vicarious traumatization.

\section{Treatment approaches to trauma}

As refugees and asylum seekers are culturally diverse and often exposed to multiple types of potentially traumatic events, it becomes difficult to define the accuracy of psychological disorders, including post-traumatic disorder. Although the $D S M-V$ has undergone number of changes in terms of PTSD formulation, it has yet to be comprehensively investigated within the context of PTSD arising from traumatic events experienced by refugees. A growing body of recent research highlights that the DSM-5 model may not best represent the symptom structure of PTSD found across both Western and non-Western culturally diverse refugee samples (Specker et al., 2018)

PTSD models such as Ehlers and Clark (2000) can be useful in understanding and treating the phenomena of PTSD in individuals. However, most trauma services require that the individual has a secure base and is no longer at risk to maximize the benefit of treatment. These criteria maybe difficult to apply to asylum seekers as they remain at very real risk of being returned to the dangers from which they fled. It could be rationalized that their anxiety is an appropriate response as they are still at risk and their trauma may be ongoing. Indeed, some research indicates that traditional trauma-focused CBT is of limited benefit to people whose status is uncertain (Bowley, 2006).

Several review studies support the use of culturally sensitive CBT and narrative exposure therapy as more effective interventions for refugee populations (Slobodin and de Jong, 2015), although there is still a need for well-designed, empirically validated research as this is still a largely unexplored area (Nose et al., 2017)

The universal validity and applicability of PTSD models on non-Western populations has been questioned by a number of researchers in this field (Bracken et al., 1995; Burnett and Peel, 2001; Summerfield, 1995; Somasundaram, 2007). They identified that worse outcomes in resettlement have been linked with post-migration experiences of leaving one's country unexpectedly and indefinitely, and by the suffering of marked losses, e.g. home, country, language, social support, shared cultural, spiritual, political, or religious views (Tribe and Keefe, 2007).

According to Papadopoulos (2007), clinicians and researchers have begun to shift their emphasis away from the symptoms of trauma/PTSD towards understanding refugees' and asylum seekers' experiences and challenges within the resettlement environment. He suggests 
that increased focus is needed on fostering strength, capacity and resilience among individuals and communities.

Overall, there is an acknowledgement among clinicians and researchers that a holistic approach which recognizes cultural differences, values, the context of a person, their resilience and the strengths and wisdom of the refugee community should be taken into consideration when providing therapy to refugees and asylum seekers (de Jong and Van Ommeren, 2009; Dossa, 2009; Gozdziak, 2004; Miller, 1999; von Peter, 2008; Papadopoulos, 2007; Somasundaram, 2007). The concept of 'post traumatic growth', positive changes and the human capacity to transform in the midst of horrific circumstances has also been noted (Saakvitne et al., 1998).

\section{Culturally adapted CBT}

All psychological treatments and scientific research are shaped according the culture of the specific population and nation. In Western culture, CBT often takes a special form where it focuses on individual/intrapsychic factors, although one's culture and community may be referenced in the formulation. However, the role and value of community in healing from trauma may not be ordinarily part of the treatment which will be primarily focused on individual symptom relief.

While CBT works for clients from most cultural backgrounds, research has shown that adapting CBT to meet the needs of specific groups increases its effectiveness. Cultural adaptation refers to the process of making therapeutic goals, language, content and process consistent with those of the target population to enhance treatment relevance, credibility and efficacy (Bernal et al., 1995; Sue and Zane, 1987).

Culturally adapted CBT (CA-CBT) has been shown to be effective in randomized controlled trials for Latino patients and for Southeast Asian refugee patients from Cambodia and Vietnam (Hinton et al., 2005; Hinton et al., 2011). A meta-analysis by Griner and Smith (2006) that examined a culturally adapted intervention across 76 studies found a moderate weighted average effect size $(d=.45)$. They reported that interventions targeted to a specific cultural group were four times more effective than interventions provided to groups consisting of clients from a variety of cultural backgrounds. Furthermore, interventions conducted in the client's native language were twice as effective as interventions conducted in English.

Two approaches to adaptation have been identified: 'top down' and 'bottom up'. The top down approach is characterized by adaptation of an existing evidence-based intervention, developed for one group, and modified for application to other groups. The bottom up approach is developed within a particular cultural context and directly addresses culturally specific concerns that are relevant for this group. The result is a new intervention (Hall et al., 2016; Hwang, 2006).

CA-CBT differs from the standard traditional treatment protocols and enables therapists to focus on the treatment challenges presented by refugee experiences and allows them to pay attention to traditional methods of healing and culture, which was an important element of the Manashanthy project, the subject of this study.

\section{Tamil culture and the civil war}

A significant number of Sri Lankan Tamils fled the violence unleashed during the civil war (1983-2009) between Tamil Freedom Fighters known as LTTE and the Sri Lankan government. The largest concentrations of Sri Lankan Tamils outside of Sri Lanka exist in Canada, USA, India, Australia and European countries including the UK.

In their report 'Torture once again rampant in the Sri Lanka Conflict', the Medical Foundation (2007) described the extent of torture used in the Sri Lankan War:

'Out of the 130 cases reviewed, 55 clients reported being beaten with implements ranging from truncheons to electric cable, 30 reported being burnt with cigarettes, and 20 said they were partially suffocated by a plastic bag soaked in petrol being placed over the head. Suspension by the ankles was also common, with 22 reported incidents. At least 12 clients 
said they were held naked in their cells and there were 14 incidents in which clients were held in solitary confinement. Falanga, the beating of the soles of the feet, occurred in 10 incidents, with a number of clients reporting that they were bound by the feet and arms and laid face down on a bench during the torture. The prevalence of rape as a method of torture was widespread among the recent group of arrivals to the UK, with at least 24 female clients and 22 male clients reporting they were raped.' [p. 5]

Similarly, Thillainathan (2010) described the terrible experiences that Tamil clients suffered in their homeland:

'Verbal, physical, sexual and psychological torture, e.g., hot chillies forced into eyes and other bodily orifices; sexual assault on both men and women (mostly anal rape for men); deprivation of food, water and light; exposure to extreme hot and cold; in general, any activity designed to degrade, dehumanize and break the spirit. If the client did not suffer torture directly in the hands of captors, they were subject to the constant threat of abductions, fear of disappearances in "white vans", the screaming death noise of air raids, and witnessing dismembered bodies lying around openly and in hiding (noticed by the smell of decaying bodies in camps).' [p. 68]

Members of the Tamil community experienced terrible trauma through the civil war in Sri Lanka, and many experience mental health issues as a result of torture, imprisonment and dislocation, often in the context of refugee status.

The extracts above reflect the experiences described by the majority of the Tamil clients who accessed Wandsworth IAPT between 2010 and 2017. These experiences led to social isolation and suspicion and fear of statutory services, presenting more barriers to them accessing support in addition to the more obvious issues of language and lack of awareness of mental health issues.

Tamils value their language to a great extent and consider it as part of their culture and identity. Tamil language is known as one of the ancient languages of the world and has been accorded the status of 'classical language of Antiquity'. The medical, psychological/psychiatric knowledge in Tamil culture is based on the Siddha system. This is not known to many professionals in mental health as the Tamil medical literature is only available in Tamil (Somasundaram, 2002; Somasundaram et al., 2015). The Siddha system (spiritual path) describes the anatomy and physiology of the mind, namely emotions, thoughts and bodily sensations and behaviours. It is explained using the chakra systems and treatments involve herbal medicine, the use of metals, martial arts, mantra chanting, breathing techniques, yoga, meditations and counselling by spiritual gurus/sages. Tamil mental health is further influenced by Buddhist teachings, philosophy and meditations especially from the Tamil literature called 'Manimekala'.

Although the Siddha system of medicine is not in use today as it was in earlier days, many of the strategies continue to be used by Tamils at home to promote physical and emotional well-being. Most of the herbal remedies and ayurvedic cooking, yoga practices and meditations are known to Tamil people. However, due to long-term conflict and displacement, the traditional cultural practices are slowly disappearing.

To meet the complex needs of our Tamil community, we developed the Manashanthy (inner peace) group programme, a therapeutic group using a culturally adapted cognitive behavioural framework. Manashanthy was developed as part of the Improving Access to Psychological Therapies initiative in Wandsworth and Merton.

\section{The Manashanthy Programme}

The Manashanthy Programme was developed as a culturally adapted CBT group programme to support Tamil clients who presented with severe anxiety and depression due to trauma. It was produced using a 'bottom up' approach within the particular cultural context of the Tamil 


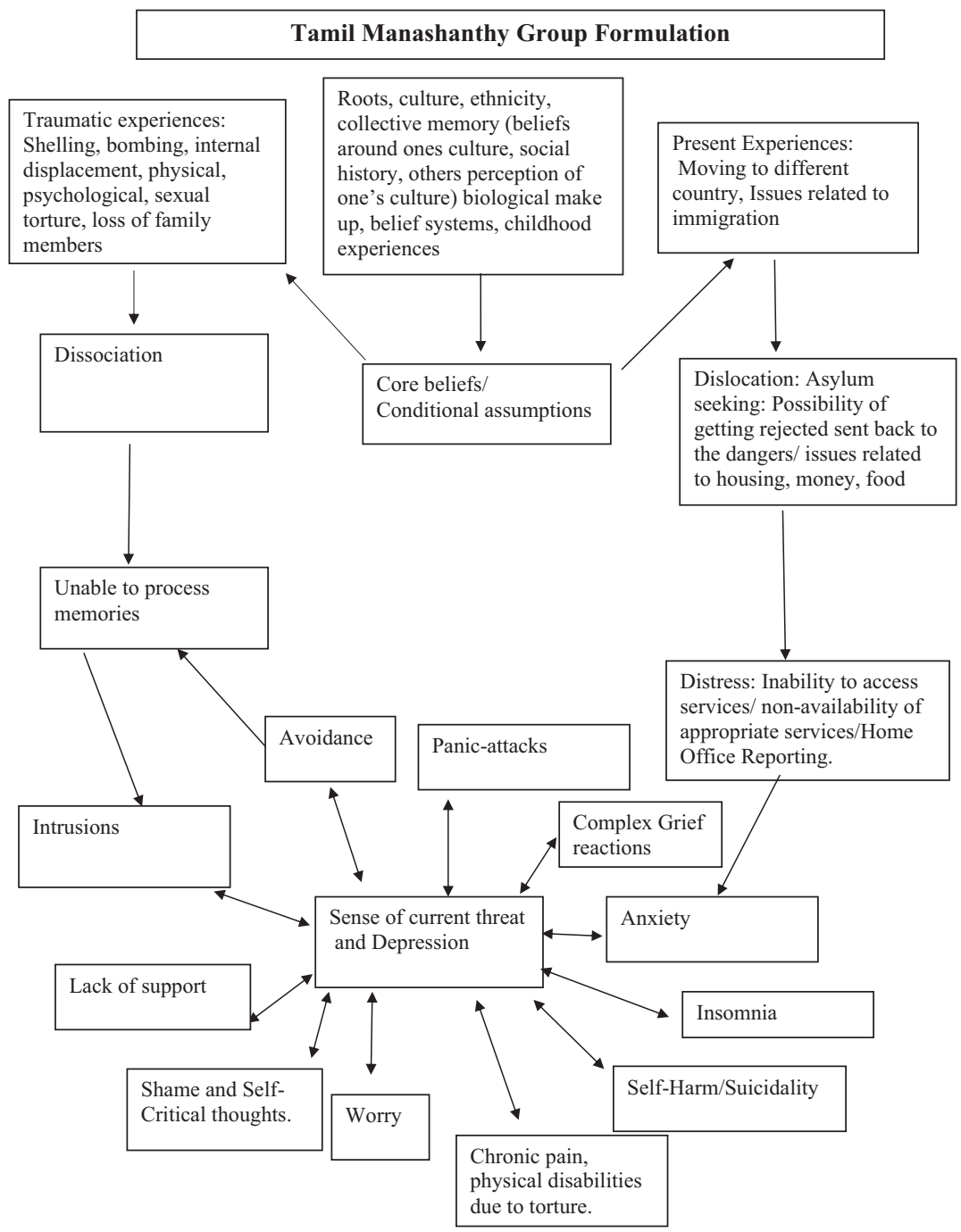

Figure 1. The Manashanthy Programme and group formulation. From Bahu (2016).

people, directly addressing psychological difficulties and culturally specific concerns that are relevant for this group. In achieving this, a number of issues were addressed:

- There was an acknowledgement that the community itself holds expertise and solutions to some difficult obstacles.

- The knowledge and awareness of the community was harnessed to both overcome stigma and create a service to meet the needs of the service users.

- Challenges were overcome to create space within an IAPT service to meet the needs of this traumatized and disadvantaged community.

- There was acceptance that delivering a service means joining with the community, learning what works for them and co-producing with them.

The aims of the Manashanthy programme were to identify the needs in the Tamil community, to work with them to bring awareness about existing IAPT services and offer tailored, culturally meaningful interventions to meet their needs. 
Tamil-speaking CBT therapists were employed and trained by the local IAPT services. They then reached out to the Tamil community by providing awareness discussions and workshops at the Wimbledon Shree Ganapathy temple as well as via other local temples and churches. This important work was supported by community leaders and community development workers and shared with local GPs to increase their awareness of what was being provided for the Tamil community.

The Manashanthy Programme was held at the Wimbledon Shree Ganapathy temple in a supportive environment in which the clients were encouraged to participate in a manner that promoted healing.

The group formulation (see Fig. 1) and therapy plan were developed through collaborative work with the Tamil clients and was discussed in detail to establish the goals of therapy. There was a shared understanding of different facets of anxiety and low mood.

Presenting issues included symptoms of PTSD, panic, worry, complex bereavement issues, chronic pain issues and suicidality. There were also issues relating to housing, financial issues and physical health problems and lack of knowledge and motivation to access supportive organizations/services in general. Due to Home Office processes and perceived hostility, there was a sense of ongoing threat of being sent back home to the dangers they had suffered. This was accompanied with thoughts of being a burden on society and feelings such as guilt, shame and fear.

Precipitating factors included shame at having had to move to a different country for survival. Furthermore, clients shared the common experiences refugees and asylum seekers face in a new host country such as racism, discrimination, home office bureaucratic processes, homelessness, and physical and mental health issues due to past traumatic experiences.

Predisposing factors included being born into a country of ethnic conflict, war, growing up in a dangerous environment with a set of cultural values and beliefs that give a sense of self/identity and resilience for survival. In terms of the Tamil groups, cultural beliefs included that it is better to die for one's country and language than leave the country. Similarly if one is tortured sexually or physically, one is stained or damaged forever and this cannot be reversed or changed through any support. Dying for motherland and language is seen as a courageous act. Escaping or moving to a different country is perceived as cowardice and accompanied by beliefs such as 'I don't deserve happiness or pleasure in life' and 'I am worthless'.

The programme therapy plan (Bahu, 2010) consisted of 12 sessions over 3 months. Each 2-hour treatment session was divided into three parts: the first part consisted of an activity (experiential) which enabled the clients to reflect upon their mood and cognitions before and after activity; the second part consisted of psychoeducation and homework practice; the final part consisted of consolidation of this work and grounding practices such as yoga or breathing.

The purpose of the adaptation of CBT therapy in this instance was to include specific Tamil cultural components in activities, and use culturally relevant imagery, proverbs, metaphor and stories in treatment so the clients could make sense of what was being offered. Input was included from the Tamil community leaders, members and clients.

To give an example, the use of the Chakra system, well known in the Tamil culture (Govindan, 2005) was used to provide a reference point for every session and provide a contextual bridge from 'traditional' to culturally adapted CBT (see detailed programme below). Similarly, behavioural activation (Rogers et al., 2002) was introduced using culturally relevant activities; relaxation techniques were incorporated using traditional healing methods such as yoga and mindfulness breathing (Emerson et al., 2009; Lilly and Hedlund, 2010; Segal et al., 2001); affective modulation and cognitive coping processes were introduced using particular Eastern breathing techniques, yoga, pranayama (breathing), creative visualizations and compassionate meditations (Hinton et al., 2005; Linehan, 1993); and collective trauma narratives (Deblinger et al., 2011) were used to promote normalization, and develop secure connections with community, supportive organizations, family and friends. 
The programme was shaped by learning from clients' and facilitators' experiences and reflections over a number of years. For example, after noticing recurrent triggers to increased risk such as Home Office assessment or sad news about lost relatives, the first two sessions of the programme were devoted to safety building and addressing suicidality. Again this was done in a way that would 'fit' with the Tamil clients. The use of the proverb Aaththirakkaaranukku budhi mattu (limited intelligence) and how this is active when one is angry (or hurt) allowed the therapists to discuss issues relating to risk, helping the clients to reflect on impulsive self-harm and attempted suicide. A safety contract in Tamil was subsequently agreed, requesting that clients do regular practice of yoga, and offering 'Kabalapati' (fire of breath), a particular breathing technique relevant in Tamil culture as an emotional regulation strategy.

The blending of traditional CBT principles and activities with Eastern philosophy and practice is illustrated in the programme plan below:

\section{Treatment sessions}

\section{Treatment sessions 1-4: Creating safety}

The first four treatment sessions of the programme aimed to establish safety. Issues relating to risk management were addressed by linking clients to a range of supportive organizations, i.e. asylum welcome so they could start applying for asylum and address basic needs such as food and accommodation; and liaison with GP and community mental health teams was supported to discuss clients' multiple needs. Culturally relevant emotional regulation techniques (breathing techniques, mantra chanting, mindful yoga) were also taught to manage impulsive self-harm/ suicide attempts.

Finally, goal setting and depression management strategies were introduced using culturally specific metaphors, stories (Buddha's arrows) and activities (culturally relevant games). The themes in chakra systems were used to communicate and psychoeducate the clients as they understood this 'language'. See Fig. 2 for a summary of sessions 1-4.

\begin{tabular}{|c|c|c|c|}
\hline $\begin{array}{l}\text { Treatment sessions } \\
1-4\end{array}$ & $\begin{array}{l}\text { Core CBT } \\
\text { components }\end{array}$ & Cultural adaptation & $\begin{array}{l}\text { Themes } \\
\text { Chakra-1,2,3 }\end{array}$ \\
\hline $\begin{array}{l}\text { Risk assessment } \\
\text { and management } \\
\text { linking with } \\
\text { supportive } \\
\text { organizations }\end{array}$ & $\begin{array}{l}\text { Assessment of risk } \\
\text { and its management. } \\
\text { Emotional regulation } \\
\text { techniques to manage } \\
\text { impulsiveacts of self- } \\
\text { harm }\end{array}$ & $\begin{array}{l}\text { Tamil metaphors and } \\
\text { stories to bring } \\
\text { awareness in relation } \\
\text { to risk. Teaching 'fire } \\
\text { of breath'practice to } \\
\text { address emotional } \\
\text { regulation }\end{array}$ & $\begin{array}{l}\text { Building trust and creating } \\
\text { a safe place. } \\
\text { Located base of spine, } \\
\text { between base of spine } \\
\text { and navel and solar } \\
\text { plexus }\end{array}$ \\
\hline Goal setting & $\begin{array}{l}\text { Collaborative goal } \\
\text { setting process }\end{array}$ & $\begin{array}{l}\text { Culturally relevant } \\
\text { games (thanga } \\
\text { veddai)/activities to } \\
\text { elicit goals and goal } \\
\text { setting process }\end{array}$ & $\begin{array}{l}\text { Cherishing/acknowledging } \\
\text { survival and existence } \\
\text { and understanding } \\
\text { ongoing needs }\end{array}$ \\
\hline $\begin{array}{l}\text { Depression } \\
\text { management }\end{array}$ & $\begin{array}{l}\text { Psychoeducation of } \\
\text { low mood. Track/trap } \\
\text { behavioural activation. } \\
\text { Pacing and planning } \\
\text { activities: addressed } \\
\text { basic needs such as } \\
\text { sleep and food,etc., } \\
\text { discussed sleep } \\
\text { hygiene }\end{array}$ & $\begin{array}{l}\text { Using culturally } \\
\text { appropriate } \\
\text { 'emotional' } \\
\text { metaphors,'Buddha's } \\
\text { arrows pain story' } \\
\text { mindful yoga }\end{array}$ & $\begin{array}{l}\text { Energy transformation: } \\
\text { how to transform the body } \\
\text { to support us to engage in } \\
\text { action. Will power and } \\
\text { motivation }\end{array}$ \\
\hline
\end{tabular}

Figure 2. Treatment sessions 1-4, core CBT components, cultural adaptation, themes. 


\section{Treatment sessions 5-7: Anxiety, stress and worry, and addressing issues related to uncertainty}

The aims of these sessions were to increase clients' emotional and cognitive flexibility and differentiate anxiety as disorder versus anxiety as rational response to ongoing threat. Further psychoeducation related to anxiety, panic and worry provided (Clark, 1986; Clark et al., 1999; Dugas et al., 1997; Salkovskis, 1991). The Eastern philosophy of impermanence (Anicca, Nilai attrathu) was used to educate clients about the nature of bodily sensations and feelings and how to be awake to their changing nature (both pleasurable and distressing). Meditations and self-enquiry were used to explore these sensations and be aware of them.

The Tamil clients experienced anxiety due to number of external issues as noted earlier. This was heightened further by worries as they faced deportation, dispersal or court hearings/legal proceedings that were ongoing. Mason's uncertainty model was used to address this (Mason, 1993). This involved exploration of how clients can create a space to work towards a 'safe uncertainty' - a much more realistic space which can cause discomfort as it involves the uncertainties of life but also a space which by its very nature is open to exploration, possibility and learning. Psychoeducation was

\begin{tabular}{|c|c|c|c|}
\hline $\begin{array}{l}\text { Treatment sessions } \\
(5-7)\end{array}$ & $\begin{array}{l}\text { Core CBT } \\
\text { components }\end{array}$ & Cultural adaptation & $\begin{array}{l}\text { Themes } \\
\text { Chakra-2 and } 3\end{array}$ \\
\hline Anxiety management & $\begin{array}{l}\text { Anxiety as a disorder } \\
\text { and anxiety as a } \\
\text { rational response to } \\
\text { ongoing threat. } \\
\text { Psychoeducation of } \\
\text { anxiety avoidance and } \\
\text { safety behaviours }\end{array}$ & $\begin{array}{l}\text { Perceptions of the } \\
\text { anxiety response in } \\
\text { Tamil culture. } \\
\text { Incorporating stories } \\
\text { and metaphors. } \\
\text { Teaching of self- } \\
\text { soothing activities } \\
\text { (kapalabadi, Anulom } \\
\text { vilom pranayama/ } \\
\text { breathing, mindful } \\
\text { meditations) }\end{array}$ & $\begin{array}{l}\text { Establishing a } \\
\text { connection with } \\
\text { feelings to } \\
\text { understand their } \\
\text { strengths and } \\
\text { weaknesses. } \\
\text { Being awake to } \\
\text { emotions so we } \\
\text { can make a choice } \\
\text { how to respond } \\
\text { instead of reacting }\end{array}$ \\
\hline Worry and uncertainty & $\begin{array}{l}\text { Advantages and } \\
\text { disadvantages of worry, } \\
\text { problem-solving } \\
\text { techniques and } \\
\text { understanding worries } \\
\text { relating to uncertainty }\end{array}$ & $\begin{array}{l}\text { Using stories of famous } \\
\text { people in Eastern } \\
\text { culture who faced } \\
\text { uncertainties, e.g. story } \\
\text { of Mahatma Gandhi. } \\
\text { Teaching of self- } \\
\text { soothing activities } \\
\text { (kapalabadi, Anulom } \\
\text { vilom pranayama/ } \\
\text { breathing, mindful } \\
\text { meditations) }\end{array}$ & $\begin{array}{l}\text { Awakening } \\
\text { creative energy to } \\
\text { respect and } \\
\text { honour the body; } \\
\text { getting in touch } \\
\text { with emotions by } \\
\text { noticing and } \\
\text { bringing kind } \\
\text { attention }\end{array}$ \\
\hline Panic attacks & $\begin{array}{l}\text { Psychoeducation panic } \\
\text { attacks using Clark's } \\
\text { model. Addressing } \\
\text { panic using cognitive } \\
\text { and behavioural } \\
\text { interventions }\end{array}$ & $\begin{array}{l}\text { Eliciting cultural } \\
\text { understanding of panic } \\
\text { ('my body is } \\
\text { permanently } \\
\text { damaged'). Using } \\
\text { Eastern psychology to } \\
\text { promote understanding } \\
\text { of anicca/maatram } \\
\text { impermanence of } \\
\text { body/body sensations }\end{array}$ & $\begin{array}{l}\text { Understanding the } \\
\text { link between } \\
\text { experiencing the } \\
\text { world with our } \\
\text { senses, reacting to } \\
\text { it with our feelings, } \\
\text { and evaluating it } \\
\text { all with our mind. } \\
\text { Noticing } \\
\text { pleasurable } \\
\text { sensations and } \\
\text { distressing } \\
\text { sensations }\end{array}$ \\
\hline
\end{tabular}

Figure 3. Treatment sessions 5-7, core CBT components, cultural adaptation, themes. 
offered relating to anxiety, panic and worry. 'Traditional' CBT problem-solving techniques were taught, with self-soothing strategies (focusing on satisfying and calming the five senses through mindful meditations, breathing techniques, positive visualizations and affirmations) and grounding techniques such as mindful yoga. See Fig. 3 for a summary of sessions 5-7.

\section{Treatment session 8-12: Understanding trauma and traumatic reactions}

Sessions 8-10 focused on the symptoms of trauma and traumatic reaction. As in previous sessions this involved managing emotional exposure and emotional regulation. Psychoeducation related to PTSD helped the clients to understand symptoms such as intrusive thoughts, flashbacks, nightmares and hypervigilance (Ehlers and Clark, 2000). Clients were able to share an overview of their experiences in the war. They were able to share stories of war, loss, grief and heroism. When clients were crying, others supported them by offering water or saying, 'don't cry we are here for you' in an environment of people coming together to support each other, with tea and biscuits being shared after reflections.

Clients were able to reflect on their strengths and how they were able to escape and survive the war. At this stage in the programme, group members were able to act as co-therapists. Compassionate meditations and visualizations were offered through which clients were able to send love to their

\begin{tabular}{|c|c|c|c|}
\hline $\begin{array}{l}\text { Treatment sessions } \\
8-12\end{array}$ & $\begin{array}{l}\text { Core CBT } \\
\text { components }\end{array}$ & Cultural adaptation & $\begin{array}{l}\text { Themes } \\
\text { Chakra-4,5,6,7 }\end{array}$ \\
\hline $\begin{array}{l}\text { Trauma } \\
\text { Traumatic reactions }\end{array}$ & $\begin{array}{l}\text { Psychoeducation of } \\
\text { PTSD, grounding } \\
\text { techniques. } \\
\text { Trauma narratives }\end{array}$ & $\begin{array}{l}\text { Offering Tamil snacks } \\
\text { and tea when clients } \\
\text { completed their story } \\
\text { telling. } \\
\text { Using Eastern } \\
\text { philosophy to make } \\
\text { sense of death and } \\
\text { dying. Compassionate } \\
\text { meditation and } \\
\text { visualization to send } \\
\text { love to those who died } \\
\text { in the war }\end{array}$ & $\begin{array}{l}\text { Location: heart, } \\
\text { throat, forehead } \\
\text { and above crown. } \\
\text { Opening the heart } \\
\text { and letting go of } \\
\text { the anger and } \\
\text { grief. Releasing } \\
\text { shame and guilt to } \\
\text { embrace positive } \\
\text { emotions such as } \\
\text { kindness and } \\
\text { compassion. } \\
\text { Opening the throat } \\
\text { and expressing } \\
\text { and } \\
\text { communicating }\end{array}$ \\
\hline Relapse prevention & $\begin{array}{l}\text { Review of the sessions. } \\
\text { Creating a blue print }\end{array}$ & $\begin{array}{l}\text { Review of the sessions } \\
\text { and blueprint was } \\
\text { created in an artistic } \\
\text { way and in Tamil }\end{array}$ & $\begin{array}{l}\text { Gaining insights } \\
\text { and seeing the } \\
\text { whole process. } \\
\text { Understanding the } \\
\text { healing and } \\
\text { benefits }\end{array}$ \\
\hline Celebration & $\begin{array}{l}\text { Narratives of the } \\
\text { journey }\end{array}$ & $\begin{array}{l}\text { Sharing stories to wider } \\
\text { group and telling } \\
\text { stories in a positive } \\
\text { manner, } \\
\text { acknowledging } \\
\text { resilience and post- } \\
\text { traumatic growth }\end{array}$ & $\begin{array}{l}\text { Connecting to the } \\
\text { wider community, } \\
\text { world, universe } \\
\text { and building up } \\
\text { relationships. } \\
\text { Acknowledging the } \\
\text { joy and suffering of } \\
\text { existence and rise } \\
\text { beyond this }\end{array}$ \\
\hline
\end{tabular}

Figure 4. Treatment sessions 8-12, core CBT components, cultural adaptation, themes. 
lost ones. Eastern philosophy was referenced to reflect on death and dying, and acknowledge the journey of the soul and rebirth when this was appropriate.

Session 11 addressed relapse prevention and session 12 was designed to celebrate the successful completion of the group programme. A lunch including a variety of Tamil dishes was held, and clients and facilitators invited others who had supported the programme (e.g. GPs, community organizations, family members, supervisors, Clinical Commissioning Group (CCG) members and clinical leads, teachers from colleges, etc.). The clients were able to share stories of their group journey and discuss their learning and growth. They were able to interact with people from different community organizations and liaise with teachers from local colleges, exploring the possibility of attending courses, etc. See Fig. 4 for a summary of sessions $8-12$.

\section{Method}

\section{Participants}

This pilot audit study was conducted with participants who had accessed care at Wandsworth IAPT, St Georges Mental Health Trust between 2014 and 2015 and subsequently completed the Manashanthy programme between 2015 and 2016.

There were 16 participants ( 10 male and six female). The age range was from 23 to 55 years, with an average age of 32 years. Fourteen participants were Hindu Tamils and two were Christian Tamils.

Participants were recruited to the study on a rolling basis and divided into three groups based on the start time of sessions. There were no drop-outs.

Participants were recruited from Tamil clients who accessed the service as a result of awareness workshops and out-reach work as described in the previous section. Tamil therapists were given Trust mobile phones so the clients could refer themselves directly. After the screening and assessment process, it was decided collaboratively whether clients were suitable for a group programme or one-to-one work. Clients who presented with high levels of risk and severity were referred to the community mental health team.

Participants were first-generation Tamils living in the UK who had left their country due to long-term ethnic conflict. Their background typically included the experience of being a refugee and asylum seeker. Most of them feared persecution in their own country and many of them had lost their community, home and livelihood. They had experienced their close family members 'disappearing' or being arrested, tortured, imprisoned or killed or may have themselves gone through such experiences. Additionally, most were dealing with several types of current stress, such as not having residency status in the UK, and no secure housing and income. They were also facing the threat of being sent back to the dangers from which they had fled, and presented with grief, worry, rumination, panic attacks, anxiety and PTSD symptoms. The majority had difficulties speaking the English language fluently.

\section{Measures}

\section{IAPT minimum data set}

IAPT clinical guidelines stipulate the administration of the minimum data set (MDS) at the beginning of each clinical session and this was incorporated into the Manashanthy Programme. The MDS consists of the PHQ-9, GAD-7, Phobia Scales, Employment Status Questionnaire and Work and Social Adjustment Scale (WSAS). The PHQ-9 is the 9-item depression scale of the Patient Heath Questionnaire, which scores each of the nine DSM-IV criteria as ' 0 ' (not at all) to ' 3 ' (nearly every day). The GAD-7 is a reliable brief scale that identifies generalized anxiety disorder and measures the severity of its symptoms. The GAD-7 score is calculated by assigning scores of $0,1,2$ and 3, to the response categories of 'not at all', 'several days', 'more than half the days' and 'nearly every day', respectively, and adding together the scores for the seven questions. The Phobia Scales assess the severity of social 
phobia, agoraphobia and other specific phobias. The IAPT Data Handbook suggests a score of 4 or above on any of these phobia scales be classified as 'clinical caseness' and 4 denotes to 'definitely avoid it'. The WSAS is a self-report scale of functional impairment caused by an identified problem. All the above questionnaires have been validated for use in Primary Care (IAPT Data Handbook, 2011).

\section{Impact of Events Scale Revised}

As this client group had high levels of PTSD symptoms, a specific measure was added to the IAPT MDS to assess changes in trauma symptoms. The IES-R was developed in 1997 by Daniel Weiss and Charles Marmar (Weiss and Marmar, 1997) to reflect the DSM-IV criteria for PTSD.

\section{Qualitative feedback}

To gather qualitative feedback, participants were asked to reflect on their experience of entering the group and finishing with the group, and then answer three general questions:

- What was useful about the programme?

- What was not useful?

- How can we improve the Manashanthy Programme?

Communication in the Tamil community is naturally verbal rather than written and so there was a strong preference from participants to give verbal feedback rather than write it down using a feedback sheet. The facilitators asked the clients if they could capture their answers by completing the feedback sheet on their behalf for future use or for possible audit purposes. The clients were happy for the facilitators to type up their answers and record their feedback.

Thematic analysis was then used to analyse the data. This provided an account of the key themes to emerge from the feedback with all of the participants. Thematic analysis is a method for identifying, analysing and reporting patterns within the data (Boyatzis, 1998). The approach and procedures for thematic analysis illustrated by Braun and Clarke (2006) were utilized in this study.

\section{Results}

\section{Quantitative analysis of all participants' data from the start to end of study}

Participants were scored for six metrics at the beginning and end of the study: PHQ-9; GAD-7; Phobia scales (Social, Panic, Specific), WSAS, SI (Suicidal Ideation PHQ-9 Q9) and IES.

A positive change indicates a reduction in the severity of negative symptoms for all metrics. The results show improvement in all areas ranging from $43 \%$ for GAD-7 to $97 \%$ for SI between the beginning and end of the study. A number of the metrics have defined threshold values that signify a patient is no longer affected by that condition. Table 1 includes the reference cut-off or threshold values for metrics (IAPT Data Handbook, 2011).

In order to understand the significant changes in clinical measures we carried out individual Wilcoxon's signed-rank tests. These data suggest significant changes in pre- and post-scores on all measures and remain significant on applying a Bonferroni correction. Effect size calculation suggests a high effect size (Cohen, 1988) and significant clinical change. The thresholds were applied to the participant PHQ-9, GAD-7 and IES scores and the results are shown in Table 2.

Using the threshold values (IAPT Data Handbook, 2011) the participants were categorized as having either recovered or not recovered. The recovery rate for PHQ-9 was 50\% and for reliable 
Table 1. Measured values for indicators at start and end of study with change and percentage change over the study duration

\begin{tabular}{lccccc}
\hline Metric & Threshold value & Start & End & Change & $\%$ change \\
\hline PHQ-9 & 10 & 19.50 & 10.12 & 9.38 & $48 \%$ \\
GAD-7 & 8 & 16.88 & 9.69 & 7.19 & $43 \%$ \\
Social phobia & 4 & 6.25 & 2.19 & 4.06 & $65 \%$ \\
Panic & 4 & 5.81 & 2.25 & 3.56 & $61 \%$ \\
Specific phobia & 4 & 5.63 & 2.19 & 3.44 & $61 \%$ \\
WSAS & $\mathrm{n} / \mathrm{a}$ & 28.50 & 16.94 & 11.56 & $41 \%$ \\
SI & $\mathrm{n} / \mathrm{a}$ & 1.88 & 0.063 & 1.817 & $97 \%$ \\
IES & 33 & 75.88 & 37.94 & 37.94 & $50 \%$ \\
\hline
\end{tabular}

The mean scores for all participants for each metric are shown. n/a, not applicable.

Table 2. Significant changes in clinical measures using Wilcoxon signed-rank tests

\begin{tabular}{lcccccc}
\hline Measure & $\begin{array}{c}\text { Mean } \\
\text { pre-treatment }\end{array}$ & $\begin{array}{c}\text { Mean } \\
\text { post-treatment }\end{array}$ & Difference & Wilcoxon's W & $p$ & $\begin{array}{c}\text { Effect size } \\
d_{\text {repeated measures, pooled }}\end{array}$ \\
\hline PHQ-9 & 21.8 & 10.1 & 11.6 & 0 & $<0.001$ & 4.01 \\
GAD-7 & 20.1 & 9.7 & 10.4 & 0 & $<0.001$ & 3.95 \\
IES-R & 84.2 & 37.9 & 46.3 & 0 & $<0.001$ & 2.91 \\
\hline
\end{tabular}

Individual Wilcoxon's signed-rank tests were carried out (calculated by: http://udel.edu/ mcdonald/statsignedrank.xls, accessed 11 April 2019); effect sizes were calculated using: http://www.psychometrica.de/effect_size.html\#repeated, accessed 11 April 2019.

Table 3. Clinically significant change (illustrating recovery rate and reliable change) ( $n=16$ for all)

\begin{tabular}{lcc}
\hline & $\begin{array}{c}\text { Recovery } \\
\text { rate }(\%)\end{array}$ & $\begin{array}{c}\text { Reliable } \\
\text { change }(\%)\end{array}$ \\
\hline PHQ-9 & 50 & 87.5 \\
GAD-7 & 12.5 & 87.5 \\
IES-R & 25 & 100 \\
\hline
\end{tabular}

change was $87.5 \%$. Furthermore, recovery rate for GAD-7 was $12.5 \%$ and $87.5 \%$ for reliable change. IES-R showed a recovery rate of $25 \%$ and reliable change of $100 \%$. Please see Table 3 .

These data suggest that although recovery rate was modest, clinically significant changes were made in the majority of participants. This potentially reflects the relative severity of presentation with this cohort.

\section{Baseline measurements}

Although there was no control group who received no treatment during the study, one approach to ascertain a baseline measurement was to use the waiting list for the group programme as a control. In particular, measurements were taken in an interim period between triage and initial assessment during which the 16 clients received no treatment (only risk management) while waiting for the programme to start. We carried out Wilcoxon's signed-rank tests (paired sample, non-parametric statistical test) to understand whether clients would have made improvements while waiting for the group approximately 3 months after triage. The data suggests $p>0.2$ for depression (PHQ-9) and $p>0.2$ (GAD-7), and they indicate no significant change prior to the group programme. In terms of IES the measures were only offered at assessment session (4 weeks prior to group programme) and not at the triage and this shows a significant change $(p<0.001)$. Fifty per cent of the participants made significant 
improvements in terms of PTSD symptoms. This could be because clients were offered psychoeducation regarding PTSD and they were offered materials in Tamil about PTSD and trauma and some coping strategies for this.

\section{Qualitative data}

The results of the thematic analysis of the group feedback are described below. Four major themes directly related to the therapeutic group emerged and are reported in this study. The major themes related to: Identity issues, Interventions, Diagnosis and measures, and Programme improvement.

Each major theme was also divided into sub-themes and these were then further divided in accordance with clients' reflections on their thought processes during the initial and later phases of the programme. This helped the researchers to identify any cognitive shift within each theme over the course of the programme.

\section{Identity: individual/cultural and collective}

Most of the group members reported a sense of loneliness and isolation in the UK. They reported that they felt like outsiders and a burden on society $(n=7)$. They reported harsh treatment, shame and lack of connection with their own community and the majority community. They also discussed Tamil cultural values, relationships and connection and how this had been severed by the war and replaced with mistrust, avoidance, aversion and anger $(n=8)$. Overall, there was a sense of loss and mourning, although at the same time there was also some acceptance of the pain and reflection related to healing $(n=10)$. See Fig. 5 for a summary of the themes.

\begin{tabular}{|c|c|c|c|}
\hline Theme & Subthemes & Examples of initial thought proc & sses/belief changes \\
\hline \multirow{5}{*}{ Identity } & \multirow[b]{2}{*}{ Individual } & Initial experience & Group processes/experience \\
\hline & & $\begin{array}{l}\text { 'Initially I didn't want to attend } \\
\text { the group as I couldn't trust } \\
\text { people' }\end{array}$ & $\begin{array}{l}\text { 'After attending the group, I } \\
\text { learned that we all had the } \\
\text { similar problems, as a } \\
\text { community we lost our culture, } \\
\text { values and respect. Coming } \\
\text { together and mourning helped } \\
\text { me establish trust' }\end{array}$ \\
\hline & Cultural & $\begin{array}{l}\text { '...I was ashamed of who I was } \\
\text { and couldn't look at the mirror' }\end{array}$ & $\begin{array}{l}\text { 'I am proud of being Tamil; the } \\
\text { oldest culture in the world and } \\
\text { rich, we are highly educated } \\
\text { people' } \\
\text { 'I am now able to look at the } \\
\text { mirror and smile' }\end{array}$ \\
\hline & $\begin{array}{l}\text { Collective } \\
\text { Resilience }\end{array}$ & $\begin{array}{l}\text { 'I never thought we will get } \\
\text { destroyed to this level. I thought } \\
\text { we will never be able to recover } \\
\text { from this' }\end{array}$ & $\begin{array}{l}\text { 'Being in this group I learned we } \\
\text { (Tamils) don't easily give up and } \\
\text { we will continue to work hard to } \\
\text { heal ourselves' } \\
\text { 'We are stronger, and we will } \\
\text { use this experience to support } \\
\text { others' }\end{array}$ \\
\hline & $\begin{array}{l}\text { Post- } \\
\text { traumatic } \\
\text { growth }\end{array}$ & $\begin{array}{l}\text { 'I isolated myself and stopped } \\
\text { talking to the family I lived with. I } \\
\text { felt like a burden. I felt I had } \\
\text { nothing to give and I am better } \\
\text { off dead.' }\end{array}$ & $\begin{array}{l}\text { 'Now I am going to the temple } \\
\text { and speaking the family I live } \\
\text { with. I am making an effort to } \\
\text { relate to people and thanks to } \\
\text { the group I have some good } \\
\text { friends now' }\end{array}$ \\
\hline
\end{tabular}

Figure 5. The theme of identity, subthemes and example of initial thought processes and belief changes. 


\section{Interventions}

All group members reported that they had benefited from the interventions that were used in the group. The majority reported that they highly benefited from psychoeducation $(n=12)$. This empowered them to understand what was happening to them. They reported they were able to make sense of why they suffered from low mood and anxiety, worrying, having panic attacks, intrusive thoughts and flashbacks, etc. They also reported that psychoeducation took away the stigma they experienced. They reported that they were scared that they were

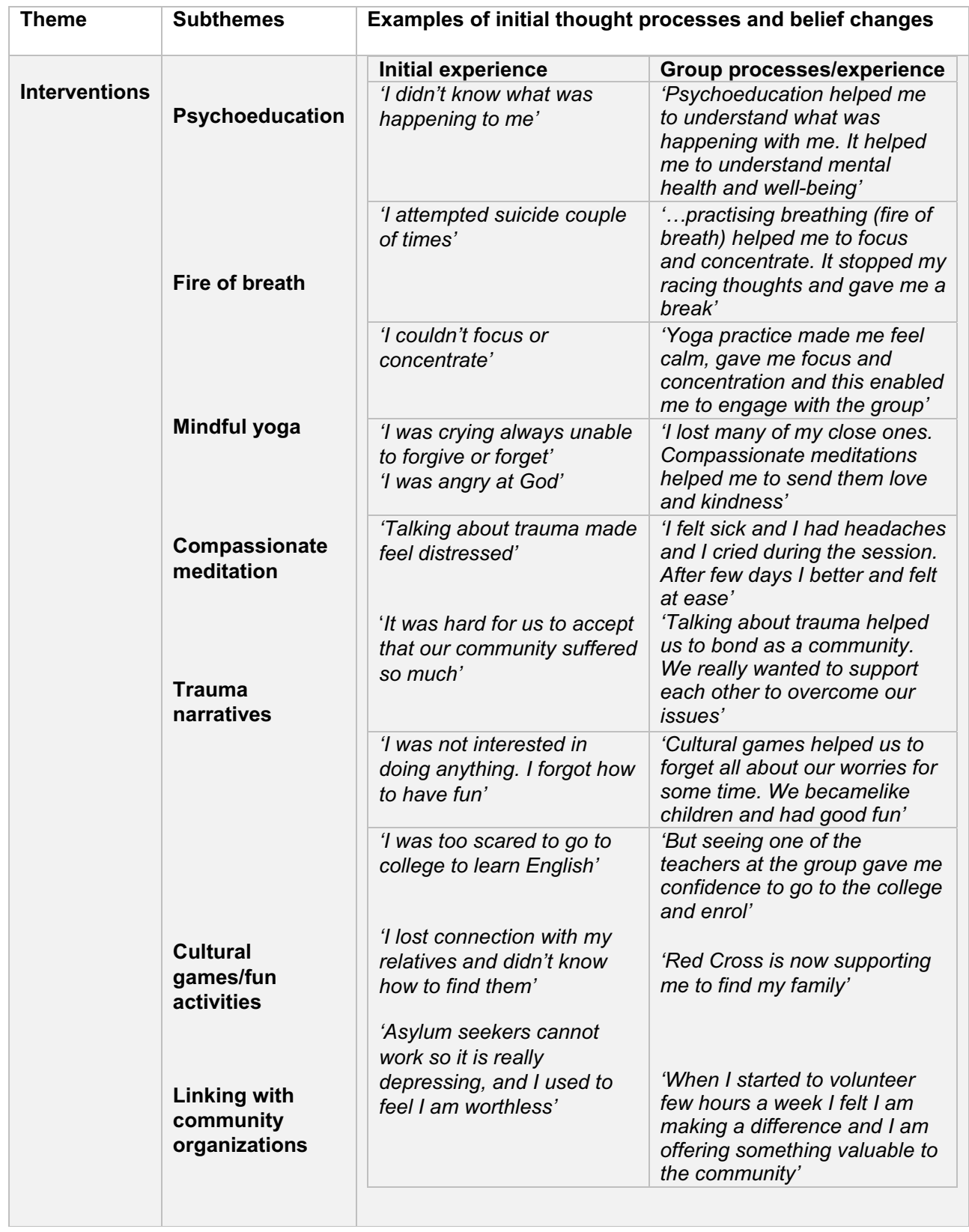

Figure 6. The theme of interventions, subthemes and example of initial thought processes and belief changes. 
suffering from a mental illness and felt quite ashamed about their mental health condition. They reported that they had benefited from knowing the differences between mental illness (pathological condition) and disorder (a disturbance in thought, feelings and behaviour that affects the mind). They also reported they felt they were more knowledgeable in terms of mental health and were able to discuss problems with their friends, family or other organizations without feeling shame $(n=14)$. They reported that yoga and meditation, fire of breath and mindfulness meditations helped them to calm down so they were able to focus on the sessions. Some participants described how the 'fire of breath' stopped them being compulsive and helped them with suicidal ideation $(n=6)$. They reported that initially they felt dizzy doing the breathing but it became better once they were established in the practice. See Fig. 6.

\section{Diagnosis/measures}

Most of the group members reflected on measures and diagnosis. They reported that they had fears relating to their diagnosis $(n=9)$. They shared that it is almost forbidden to discuss mental health issues at home $(n=10)$. They shared they did not tell their family members or friends or flatmates that they were tortured sexually and physically. They reported shame and

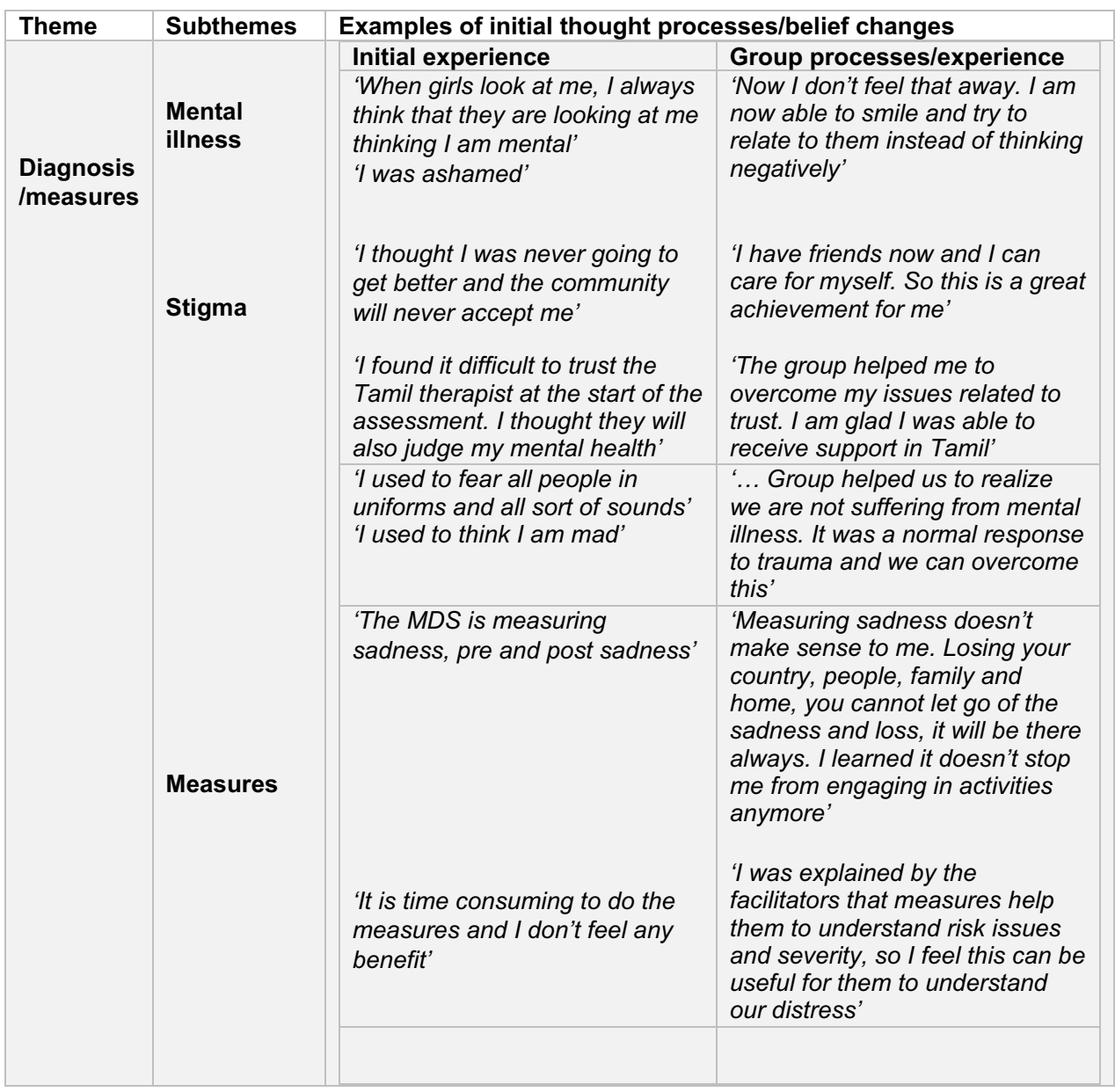

Figure 7. The theme of diagnosis and measures, subthemes and example of initial thought processes and belief changes. 
vulnerability discussing these issues with others. Furthermore, they shared that they did not want to hurt their family members' feelings by sharing details.

The group reported that problems are usually kept as a secret and rarely explored within the family context. Family members often encouraged them to forget the past and not to think about it anymore. They also discouraged them from sharing their problems with others/friends. There was a general fear that the community would discriminate against all family members, avoid and stigmatize them. They reported that because of one family member, the whole family would receive a diagnosis as a 'visar family' (mad family) and they would be discriminated against in marriage arrangements.

In terms of measures, group members reported that they felt some of the measures were not relevant for them as they were not measuring disordered thinking, i.e. worrying too much about different things or being unable to stop worrying. They felt there was a reality to their worry concerning such issues as housing, jobs, education and Home Office reporting and the threat of being sent home.

In particular, they noted that it was hard for them to put a number to their feelings. However, they acknowledged that this helped the facilitators identity risk-related issues and their level of distress in general.

Participants $(n=7)$ expressed that it was important to feel sad and anxious regarding their situation and important to be able to express this. They reported that prior to the group, they were simply lost in their thoughts, distractions and inaction. They added that they suffered from trust issues and emotional numbing. They also shared a deep distrust and fear towards their own community; attending the group had changed their perception They also acknowledged that their sense of sadness and anxiety had shifted since attending the group, although they believed it was realistic to think that some sadness and loss would always be there.

They added it was important for them to remain aware of how they were still in danger and highly threatened by Home Office reporting processes; that their trauma was continuing in a different form and was not a form mental illness but reality. However, they also added they were no longer frightened to engage in daily activities, attend appointments, go out, use public transport, study, and seek support from different organizations. As a group they reported that they felt that they had benefited from the group interventions as reflected in the measures. See Fig. 7.

\section{Group-led programme improvement}

The group reported they would benefit from longer term support (e.g. increasing the session numbers and offering individual sessions when they go through high levels of distress). They also requested day trips to travel to museums, art galleries, the beach, restaurants and Tamil

\begin{tabular}{|c|c|c|c|}
\hline Theme & Subthemes & Examples of initial though & cesses/belief changes \\
\hline \multirow{3}{*}{$\begin{array}{l}\text { Improvements } \\
\text { to the group }\end{array}$} & \multirow{3}{*}{$\begin{array}{l}\text { Time } \\
\text { Outdoor } \\
\text { sessions } \\
\text { Session } \\
\text { numbers }\end{array}$} & Initial experience & $\begin{array}{l}\text { Group } \\
\text { processes/experiences }\end{array}$ \\
\hline & & $\begin{array}{l}\text { 'I was attending the group } \\
\text { initially but didn't have full } \\
\text { understanding of the } \\
\text { programme' }\end{array}$ & $\begin{array}{l}\text { 'Only after } 6 \text { th session I } \\
\text { started to feel the benefits and } \\
\text { understood the sessions, I } \\
\text { wish we had more sessions } \\
\text { and ongoing drop-ins or } \\
\text { meetings' }\end{array}$ \\
\hline & & $\begin{array}{l}\text { 'I wanted us to go out as a } \\
\text { group' }\end{array}$ & $\begin{array}{l}\text { 'It would have been nice if we } \\
\text { had outdoor sessions. I would } \\
\text { have liked us to go out as a } \\
\text { group and see the museums } \\
\text { and galleries' }\end{array}$ \\
\hline
\end{tabular}

Figure 8. The theme of programme improvement, subthemes and example of initial thought processes and belief changes. 
cinema so they could have fun as a group $(n=11)$. They reported that they felt safer when the group facilitators were present and able to support them if they 'got lost' or went through a difficult time with the police, etc. There was an overall desire to understand the majority culture and the group was curious about places and travelling. This was not present at the start of the group. They reported that it was useful to have a previous member speak about the group processes at the start of the group and inform about homework practices. They added this would motivate them to engage with the homework practices. See Fig. 8.

\section{Discussion, conclusion and implications for further research}

Members of the refugee population are likely to experience innumerable traumatic experiences that will have negative consequences for their mental health. These mental health issues need to be addressed in the host country to ensure that refugees and asylum seekers can live and experience productive and fulfilling lives (Hollifield et al., 2002).

\section{Culturally adapted CBT}

This study described how a culturally adapted CBT therapy programme was developed through collaborative efforts with the Wandsworth Tamil community over a period of years during which the Manashanthy Programme and interventions evolved. This process ensured that key aspects of the culture were incorporated into the rationale and development of the CBT approach and programme interventions.

The outcome measures of this study suggest significant improvement in terms of mood and anxiety for the 16 participants from the local Tamil community.

The data analysis suggests that the recovery rate for PHQ-9 is $50 \%$ and for reliable change is $87.5 \%$. Furthermore for GAD-7, there was a $12.5 \%$ recovery rate and $87.5 \%$ reliable change. IES-R showed a recovery rate of $25 \%$ and reliable change of $100 \%$.

Although the recovery rates are modest, the data suggest clinically significant reliable changes made on all measures. It is possible this is because the participants were still under the threat of being sent back to their homeland and the dangers that remained there. Participants also continued to experience uncertainties relating to their housing and employment. It is also interesting to note that the group did not make any recovery or significant improvements on PHQ-9 or GAD-7 from triage period to start of the group (approximately 3 months wait period). However, it is interesting to notice that $50 \%$ of the participants made reliable changes in terms of IES-R from the assessment period to group start (approximate 4 weeks), although no recovery. This could be because participants were offered psychoeducational materials in Tamil terms of trauma and PTSD and this included coping strategies.

Both quantitative and qualitative feedback indicated improvement in avoidance in relation to social situations, due to panic symptoms, or specific phobias. Clients reported that they were now able to use public transport and travel. This was very important for those who had been confined indoors for many years as a result of high levels of anxiety.

Results from the WSAS measure indicated a $41 \%$ improvement overall. Although many of the participants were interested in finding a job and contributing to their new community, they reported being unable to do this due to legal restrictions on refugees. Most of the participants reported that they had been working in Sri Lanka in different professions. They described losing their job as a major personal loss.

In terms of family and relationships, many participants reported being unsure as to what had happened to their family and they were in the process of finding out where they were and whether they were alive, all of which contributed to an impaired ability to form and maintain current relationships.

The qualitative feedback indicates some thoughts/belief changes, the role of the group identity and the sense of coming together as a community was noted as being important. This could be one 
of the reasons for a high level of engagement in the programme as there were no drop-outs. Feedback also supported the concept of pos-traumatic growth (Saakvitne et al., 1998) with the group reporting personal growth and rediscovering their identity during their struggle to heal.

Participants also reported that they benefited from all the interventions. The majority shared that they highly benefited from yoga, meditation, breathing practices and psychoeducation. Yoga and meditation are practices that are valued in the Tamil culture and participants found that they were able to connect with their culture via these practices. They also highlighted the benefits of a breathing practice, the fire of breathing. Participants reported that this type of breathing helped in regulating their emotions, particularly reducing compulsive acts such as suicide attempts.

In relation to the impact of diagnosis and measures, the usefulness of this to the individual was expressed. While not always sure that measures used were relevant for their presenting problems, participants recognized the assessment of risk as being important.

All clients reported that the sessions were packed with information and they would have benefited more from the group had it been extended to over 16 sessions.

Although this study was not a randomized controlled trial, the quantitative results and the qualitative feedback supports the efficacy of culturally adapted CBT as indicated by the studies previously discussed (Beck, 2016; Hinton et al., 2005; Hinton et al., 2011).

Furthermore, the collective trauma approach as discussed by Somasundaram (2007) and bringing communities together to foster strength, capacity and promote resilience among individuals would seem to be relevant and supported by the results of the present study. Results also seem to support the view that trauma-focused CBT alone (Ehlers and Clark, 2000) is of limited benefit to people whose status is uncertain (Bowley, 2006). However, the researchers would like to note that a trauma-focused CBT framework was relevant during the programme and useful in explaining PTSD symptoms, offering psychoeducation and addressing some avoidance behaviours.

\section{Establishment of trust and engagement}

As explained in the Results section, there were no drop-outs from the programme. The Manashathy groups took place in temple and a church to counteract ideas of stigma. Culturally Tamils (both Hindus and Christians) respect a place of god. Participants were able to make use of the kitchens to make tea and coffee and felt they were in a compassionate place, a place of worship where they felt safe.

As sessions progressed, group members acted as co-therapists and agreed that they would motivate each other to attend the group and review each other's homework. They also showed great concerns for other members, e.g. if they knew that a member of the group would be attending Home Office reporting, they would remind them that they would be thinking of them until the next session, fostering relationships and a sense of community.

Also, according to cultural norms, participants addressed each other as brother, sister or mother, or father according to their age. Perhaps age also played a factor in creating a community approach as the young clients were quite respectful of the older clients and tried to act as their children and make tea and ensure they had biscuits, etc. The older clients would also encourage young clients and encourage them to work hard to overcome their difficulties. Although the clinicians were addressed as 'doctor' at the start of the group, in the middle of the sessions the therapists were addressed as big sister (Akka). Overall the creation of a safe place and establishing of respectful, culturally appropriate relationships encouraged the establishment of trust and engagement.

\section{Risk}

Participants experienced high levels of distress and needed lots of support in managing risk and maintaining their safety. Although in many ways this group would be more appropriately managed in secondary care services, in this instance they were being managed as a group in a primary care IAPT service. Containment of risk and difficult emotions was paramount for both 
clients and the therapists. It was important that therapists could access high-quality supervision and support and that clients had access to crisis/secondary care support when it was necessary. Therefore an effective relationship between clinicians in both primary and secondary care services was essential and a clear pathway for referral needed to be in place so there was no confused accountability for clinicians managing client safety.

\section{Impact of the work on facilitators}

This study did not explore the impact of the work on facilitators; nevertheless, the following observations are worthy of note. There were huge rewards from working with refugees and asylum seekers. However, high demands of the work (including client's basic needs such as housing, benefits and food) also had an impact on the clinician's emotional resources, with clinicians often feeling powerless and helpless to support their clients.

Similarly, most NHS mental health services can only offer a limited number of sessions and clinicians may experience a 'sense of abandoning' their clients before being able to address these complex problems appropriately.

Issues relating to vicarious trauma (van der Veer, 1998) also need to be explored further. It is important that therapists engaged in this work are contained and supported such that they are able to provide a safe and effective service to the clients while maintaining their own wellbeing.

\section{Use of supervision}

It is very important to note that strong clinical supervision was needed during this study both to ensure appropriate treatment protocol for clients, but also containment for therapists and supervisors. A balance needed to be achieved between the supervisor understanding the needs of the client group and the needs of the therapists. It is important to recognize the impact of this complex and emotionally demanding work, the impact of client/group transference (or strong core-beliefs being evoked in therapists/supervisors) and maintaining a 'distance' for effective, objective supervision. Supervision with therapists working with clients who present with trauma is important in order to prevent vicarious trauma and burn-out, and to support the client work and self-care as noted by van der Veer (1998) and Hawkins and Shohet (2012). If possible the use of specialist trauma and culturally sensitive supervision is recommended as suggested by Beck (2016).

\section{Relationship with other organizations}

This study highlights the importance of connection and the relationship with community organizations. A further study could explore the impact of relationship building with other organizations to offer safe and sound services to refugee clients. It is important to link and connect with the GPs, and have an additional conduit to secondary care services. As refugee and asylum-seeking clients have additional needs such as housing and financial support, it is important they can be signposted to relevant organizations who can offer practical support. This important topic was integrated into the group programme as many participants were afraid of approaching organizations fearing it might jeopardize their asylum processes.

\section{For service considerations}

Relevant and adequately resources should be provided to protect both clients and clinicians for this rewarding but demanding work. As noted, this particular programme took place within an IAPT service and it may be interesting to explore the impact of this context on service users.

The quantitative measures that are standard in IAPT may not be appropriate or sensitive for this group as they may not measure accurately the lived experience of refugees and asylum seekers. Although the measures are useful to know how clients are progressing on some aspects of 
wellbeing, they may not accurately measure the progress they have made in general, or capture the unique challenges faced.

The Centre for Psychological Therapies in Primary Care (CPTPC) carried out qualitative interviews with providers and commissioners in the first tranche of areas implementing the Government's Any Qualified Provider (AQP) policy in 2013. The study found that there was considerable scepticism about over-reliance on the measures in general for the population in the UK. There was a discussion that measurement was 'a snapshot' in time which might produce different results within 24 hours. There may also be unfair ethical pressures created by payment for IAPT services being dependent on a positive outcome and non-recognition of fluctuation in well-being during a course of treatment. In the caseload supervision for IAPT staff, this can also cause additional pressure to clinicians who are managing distressed clients with complex needs who may not be achieving recovery, and there may be pressure to discharge them.

Acknowledgements. A special thank you to Dr Janet Dutton for the significant time invested in supervising and guiding this project to completion. I am grateful to Dr Jane Street for assistance in auditing the project and Dr Stephen Logan and Dr Andre Lynam Smith for analysing the data for this group. I would like to thank all my colleagues at St Georges Mental Health Trust, Wandsworth IAPT service, supervisors, managers and members of the BABCP's Equality and Culture Special Interest group; also Mark Collinson, Shikainah Samuel, Darren Fernandes, Elicia Mollineau, Geetha Mahesvaran and Pastor Freddie Brown for their kind assistance in organizing with the Tamil Group. Thank you to Dr Michael Worrell and Krish Nath for all the encouragement and support. Finally thanks to Amma for giving me inspiration to do this work and all the Tamil clients for their rich contributions.

Financial support. No financial support was received.

Conflicts of interest. None.

Ethical statement. Ethical approval was requested but the authors were informed this was not necessary as this was a service audit/evaluation.

Key practice points. The study aimed to provide a shared understanding of difficulties experienced by refugees and asylum seekers and the issues related to psychological treatments. The study investigated a culturally adapted CBT programme for Tamil refugees and asylum seekers and recommended the following:

(1) Co-production with communities ensures interventions that are tailored to the local needs and improvement of access.

(2) Listening to service users and offering what they need, allows appropriate interventions to be developed - culturally adapted CBT in this case, compared with imposing 'ready-made' therapeutic approaches.

(3) Service Key Performance Indicators (KPIs) need to be flexible to enable innovative working.

(4) NHS organizational support is necessary to create innovative projects and to offer appropriate/specialist supervision and support to the staff. This would protect the clinicians and prevent burn-out.

\section{Further reading}

Beck, A. (2016). Transcultural Cognitive Behavioural Therapy for Anxiety and Depression: A Practical Guide. London, UK: Routledge.

\section{References}

Amnesty International (2004). Get it right. How Home Office decision making fails refugees. Retrieved from: https://www. amnesty.org.uk/files/get_it_right_0.pdf

Asylum Aid (1999). Still no reason at all Home Office decisions on asylum claims. Retrieved from: https://www.asylumaid.org. uk/wpcontent/uploads/2013/02.old/Still_No_Reason_At_All.pdf

Asylum Information Database (2018). Updated report on recent developments in UK asylum practice and law published. Retrieved from: https://www.ein.org.uk/news/updated-report-recent-developments-uk-asylum-practice-and-law-published

Bahu, M. J. (2010). Manashanthy Group programme; formulation, treatment and strategies. South West London St Georges Mental Health Trust, Wandsworth IAPT. Unpublished. 
Bahu, M. J. (2016). Culturally adapted cognitive behavioural programme for Tamil people in South West London in Crisis Care Summit London. Retrieved from: http://healthylondon.org/hlp-archive/sites/default/files/Manashanthy.pdf

Beck, A. (2016). Transcultural Cognitive Behavioural Therapy for Anxiety and Depression: A Practical Guide. London, UK: Routledge.

Beiser, M., \& Hou, F. (2001). Language acquisition, unemployment and depressive disorder among Southeast Asian refugees: a 10-year study. Social Science \& Medicine, 53, 1321-1334.

Bernal, G., Bonilla, J., \& Bellido, C. (1995). Ecological validity and cultural sensitivity for outcome research: issues for cultural adaptation and development of psychosocial treatments with Hispanics. Journal of Abnormal Child Psychology, 23, 67-82.

Bowley, J. (2006). Working with asylum seekers. In N. Tarrier (ed), Case Formulation in Cognitive Behaviour Therapy: The Treatment of Challenging and Complex Cases (pp. 330-348. London, UK: Routledge.

Boyatzis, R. E. (1998). Transforming Qualitative Information: Thematic Analysis and Code Development. Thousand Oaks, CA, USA: Sage Publications.

Bracken, P. J., Giller, J. E., \& Summerfield, D. (1995). Psychological responses to war and atrocity: the limitations of current concepts. Social Science and Medicine, 40, 1073-1082.

Braun, V., \& Clarke, V. (2006). Using thematic analysis in psychology. Qualitative Research in Psychology, 3, 77-101.

Brown, L.V., Russell, J., \& Thornton, C. (1999). The process of disclosure in abused eating disordered patients: a preliminary survey of hospital experiences. European Eating Disorders Review, 7, 179-192.

Burnett, A., \& Peel, M. (2001). Asylum seekers and refugees in Britain. The health of survivors of torture and organised violence. British Medical Journal, 322, 606-609.

Clark, D. M. (1986). A cognitive approach to panic. Behaviour Research and Therapy, 24, 461-470.

Clark, D. M., Salkovskis, P. M., Hackmann, A., Wells, A., Ludgate, J., \& Gelder, M. (1999). Brief cognitive therapy for panic disorder. Journal of Consulting and Clinical Psychology, 67, 583-589.

Cohen, J. (1988). Statistical Power Analysis for the Behavioural Sciences (2nd edn). Hillsdale, NJ, USA: Lawrence Earlbaum Associates.

Colic-Peisker, V., \& Walker, I. (2003). Human capital, acculturation and social identity: Bosnian refugees in Australia. Journal of Community and Applied Social Psychology, 13, 337-360.

Deblinger, E., Mannarino, A. P., Cohen, J. A., Runyon, M. K., \& Steer, R. A. (2011). Trauma-focused cognitive behavioral therapy for children: impact of the trauma narrative and treatment length. Depression and Anxiety, 28, 67-75

de Jong, J. T. V. M., \& van Ommeren, M. (2009). Toward a culture-informed epidemiology: combining qualitative and quantitative research in transcultural contexts. Transcultural Psychiatry, 39, 422-433.

Derlega, V. J., Metts, S., Petronio, S., \& Margulis, S. T. (1993). Self-Disclosure. Newbury Park, CA, USA: Sage Publications.

Dossa, P. (2009). Racialized Bodies, Disabling Worlds: Storied Lives of Immigrant Muslim Women. Toronto, Canada: University of Toronto Press.

Dugas, M. J., Freeston, M. H., \& Ladouceur, R. (1997). Intolerance of uncertainty and problem orientation in worry. Cognitive Therapy and Research, 21, 593-606.

Ehlers, A., \& Clarke, D. M. (2000). A cognitive model of post traumatic stress disorder. Behaviour Research and Therapy, 38, 319-345.

Emerson, D., Sharma, R., Chaudhry, S., \& Turner, J. (2009). Trauma-sensitive yoga: principles, practice, and research. International Journal of Yoga Therapy, 19, 123-128.

Farber, B. A., \& Hall, D. (2002). Disclosure to therapists: what is and is not discussed in psychotherapy. Journal of Clinical Psychology, 58, 359-370.

Fazel, M., Wheeler, J., \& Danesh, J. (2005). Prevalence of serious mental disorder in 7000 refugees resettled in western countries: a systematic review. Lancet, 365, 1309-1314.

Govindan, M. (2005). Kriya Yoga Sutras of Patañjali and the Siddhas. Eastman: Kriya Yoga.

Gozdziak, E. M. (2004). Training refugee mental health providers: ethnography as a bride to multicultural practice. Human Organization, 63, 203-210.

Griner, D., \& Smith, T. B. (2006). Culturally adapted mental health interventions: a meta-analytic review. Psychotherapy: Theory, Research, Practice, Training, 43, 531-548.

Gurtman, M. B. (1992). Trust, distrust, and interpersonal problems: a circumplex analysis. Journal of Personality and Social Psychology, 62, 989-1002.

Hall, G. C. N., Yip, T., \& Zárate, M. A. (2016). On becoming multicultural in a monocultural research world: a conceptual approach to studying ethnocultural diversity. American Psychologist, 71, 40-51. http://dx.doi.org/10.1037/a0039734

Hawkins, P., \& Shohet, R. (2012). Supervision in the Helping Professions, 4th edn. Maidenhead, UK: Open University Press.

Herlihy, J. (2003). Refugees seeking asylum: understanding the process and seeking the need for change. Traumatic Stress Points (News for the International Society for Traumatic Stress Studies), 17, 6.

Hinton, D. E., Chhean, D., Pich, V., Safren, S. A., Hofmann, S. G., \& Pollack, M. H. (2005). A randomized controlled trial of cognitive-behavior therapy for Cambodian refugees with treatment-resistant PTSD and panic attacks: a cross-over design. Journal of Traumatic Stress, 18, 617-629. 
Hinton, D. E., Hofmann, S. G., Rivera, E., Otto, M. W., \& Pollack, M. H. (2011). Culturally adapted CBT for Latino women with treatment-resistant PTSD: a pilot study comparing CA-CBT to applied muscle relaxation. Behaviour Research and Therapy, 49, 275-280.

Hollifield, M., Warner, T. D., Lian, N., Krakow, B., Jenkins, J. H., Kesler, J., Stevenson, J., \& Westermeyer, J. (2002). Measuring trauma and health status in refugees: a critical review. Journal of the American Medical Association, 288, 611-621.

Hwang, W. (2006). The psychotherapy adaptation and modification framework: application to Asian Americans. American Psychologist, 61, 702-715. http://dx.doi.org/10.1037/0003066X.61.7.702

Laws, A., \& Patsalides, B. (1997). Medical and psychological examination of women seeking asylum: documentation of human rights abuses. Journal of the American Medical Women's Association, 52, 185-187.

Lilly, M., \& Hedlund, J. (2010). Healing childhood sexual abuse with yoga. International Journal of Yoga Therapy, 20, 120-130.

Linehan, M. M. (1993). Cognitive-behavioural treatment of borderline personality disorder. New York, USA: Guilford Press.

Mason, B. (1993). The human systems: towards positions of safe uncertainty. Journal of Systemic Consultation and Management, 4, 189-200

McNulty, C., \& Wardle, J. (1994). Adult disclosure of sexual abuse: a primary cause of psychological distress? Child Abuse and Neglect, 18, 549-555.

Medical Foundation (2007). Torture once again rampant in the Sri Lanka conflict. Retrieved from: https://www. freedomfromtorture.org/sites/default/files/documents/Torture\%20once\%20again\%20rampant\%20in\%20the\%20Sri\%20Lanka $\% 20$ conflict.pdf

Miller, K. E. (1999). Rethinking a familiar model: psychotherapy and the mental health of refugees. Journal of Contemporary Psychotherapy, 29, 283-304.

Miller, K. E., Weine, S. M., Ramic, A., Brkic, N., Djuric Bjedic, Z., Smajkic, A., Boskailo, E., \& Worthington, G. (2002). The relative contribution of war experiences and exile-related stressors to levels of psychological distress among Bosnian refugees. Journal of Traumatic Stress, 15, 377-387.

Moisander, P. A., \& Edston, E. (2003). Torture and its sequel - a comparison between victims from six countries. Forensic Science International, 137, 133-140.

Mollica, R. F., Sarajilic, N., Chernoff, M., Lavelle, J., Vukovic, I.S., \& Massagli, M. P. (2001). Longitudinal study of psychiatric symptoms, disability, mortality, and emigration among Bosnian refugees. Journal of the American Medical Association, 286, 546-554.

No-Deportations - Residence Papers for All (2018, 24 January). No-Deportations. Retrieved from: http://www.nodeportations.org.uk/Media-6-4-2011/DeathInRemovalCentres.html

Nose, M., Ballette, F., Bighelli, I., Turrini, G., Purgato, M., Tol, W., Priebe, S., \& Barbui, C. (2017). Psychosocial interventions for post-traumatic stress disorder in refugees and asylum seekers resettled in high-income countries: systematic review and meta-analysis. https://doi.org/10.1371/journal.pone.0171030 Retrieved from: http://journals.plos. org/plosone/article?id=10.1371/journal.pone.0171030

Papadopoulos, R. K. (2007). Refugees, trauma and adversity-activated development. European Journal of Psychotherapy and Counselling, 9, 301-312.

Porter, M., \& Haslam, N. (2005). Predisplacement and postdisplacement factors associated with mental health of refugees and internally displaced persons: a meta-analysis. Journal of the American Medical Association, 294, 602-612.

Rogers, P., Curran, J. \& Gournay, K. (2002). Depression: nature and treatment using behavioural activation (Part One). Mental Health Practice, 5, 32-38.

Saakvitne, K. W., Tennen, H., \& Affleck, G. (1998). Exploring thriving in the context of clinical trauma theory: constructivist self development theory. Journal of Social Issues, 54, 279-299. doi: 10.1111/j.1540-4560.1998.tb01219.x

Salkovskis, P. M. (1991). The importance of behaviour in the maintenance of anxiety and panic: a cognitive account. Behavioural Psychotherapy, 19, 6-19.

Segal, Z. V., Williams, J. M. G., \& Teasdale, J. D. (2001). Mindfulness-Based Cognitive Therapy for Depression: A New Approach to Preventing Relapse. New York, USA: Guilford Press.

Slobodin, O., \& de Jong, J. T. (2015). Mental health interventions for traumatized asylum seekers and refugees: what do we know about their efficacy? The International Journal of Social Psychiatry, 61, 17-26.

Smith, E. (2004). Right first time? London: Medical Foundation for the Care of Victims of Torture. Retrieved from: https:// www.freedomfromtorture.org/sites/default/files/documents/Right\%20first\%20time2004_singles1.pdf

Somasundaram, D. (2007). Collective trauma in northern Sri Lanka: a qualitative psychosocialecological study. International Journal of Mental Health Systems, 1, 5.

Somasundaram, O. (2002). Psychiatric thoughts in Tamil culture. Indian Journal of Psychiatry, 44, 165-169.

Somasundaram, O., Tejus, M., \& Vijaya, R. (2015). Mental health: concepts and treatment in the Siddha (Tamil) system of medicine. ASEAN Journal of Psychiatry, 16, 265-270.

Specker, P., Liddell, B., Byrow, Y., Bryant, R., \& Nickerson, A. (2018). A factor analytic investigation of DSM-5 PTSD symptoms in a culturally diverse sample of refugees resettled in Australia. Conflict and Health, 12. Retrieved from: https://conflictandhealth.biomedcentral.com/articles/10.1186/s13031-018-0155-Z 
Sue, S., \& Zane, N. (1987). The role of culture and cultural techniques in psychotherapy. A critique and reformulation. American Psychologist, 42, 37-45.

Summerfield, D. (1995). Addressing human responses to war and atrocity: major challenges in research and practices and the limitations of Western psychiatric models. In R. J. Kleber, C. R. Figley \& B. P. R. Gerson (eds), Beyond Trauma (pp. 17-29). New York, USA: Plenum Press.

Taylor, D. (2016). Suicide attempts at UK immigration removal centres at all-time high. The Guardian. Retrieved from: https:// www.theguardian.com/uk-news/2016/apr/04/suicide-attempts-uk-immigration-removal-centres-all-time-high-home-officefigures

The IAPT Data Handbook (2011). Guidance on recording and monitoring outcomes to support local evidence-based practice. Retrieved from: https://webarchive.nationalarchives.gov.uk/20160302160058/http:/www.iapt.nhs.uk/silo/files/ iapt-data-handbook-v2.pdf

Thillainathan, R. (2010). Counselling Tamil Sri Lankans. Psychotherapy in Australia, 16, 4. Retrieved from: http://www. psychotherapy.com.au/fileadmin/site_files/pdfs/InterfaceAugust2010.pdf

Tribe, R., \& Keefe, A. (2007) Editorial introduction. European Journal of Psychotherapy and Counselling, 9, 247-253

United Nations High Commissioner for Refugees (UNCHR) (1992). Handbook on procedures and criteria for determining refugee status under the 1951 Convention and the 1967 protocol relating to the status of refugees. Retrieved from: http:// www.unhcr.org/4d93528a9.pdf

United Nations High Commissioner for Refugees (UNCHR) (2016). Global Trends Forced Displacement in 2016. Retrieved from: http://www.unhcr.org/globaltrends2016/

van der Veer, G. (1998). Specific issues in working with refugees. In G. van der Veer (ed.), Counselling and Therapy with Refugees and Victims of Trauma (pp. 161-168). John Wiley \& Sons: Chichester, UK.

von Peter, S. (2008). The experience of 'mental trauma' and its transcultural application. Transcultural Psychiatry, 45, 639-651.

Weiss, D. S., \& Marmar, C. R. (1997). The Impact of Event Scale-Revised. In J. P. Wilson \& T. M. Keane (eds), Assessing Psychological Trauma and PTSD: A Practitioner's Handbook (pp. 399-411). New York, USA: Guilford Press.

Cite this article: Bahu M. War, trauma and culture: working with Tamil refugees and asylum seekers using culturally adapted CBT. The Cognitive Behaviour Therapist. https://doi.org/10.1017/S1754470X1900031X 